\title{
A Before-After Study of the Impact of a Road Safety Training Program on Professional Drivers
}

\author{
Giannis Adamos ${ }^{1}$ and Eftihia Nathanail ${ }^{2}$ \\ University of Thessaly, Department of Civil Engineering \\ ${ }^{1}$ giadamos@civ.uth.gr, ${ }^{2}$ enath@uth.gr
}

\begin{abstract}
There is growing evidence that driving fatigue is a major road safety problem, causing accidents, which frequently involve fatalities and severe injuries. Professional drivers are among the road users that are defined by literature as of high risk to get involved in a fatigue-related accident. Acknowledging the findings of an extensive state-of-the-art review, the Traffic, Transportation and Logistics Laboratory of University of Thessaly implemented a training program on driving fatigue, targeting 162 professional drivers of a leading company in building materials in Greece. Through a questionnaire survey, data were collected before and after the program realization, allowing the assessment of potential behavioral changes. The impact of the training program was evaluated with the usage of descriptive and inferential statistics. Results showed that the program affected trainees' behavior in the positive direction of change, resulting in a statistically significant increase of the average frequency that they follow effective fatigue countermeasures.
\end{abstract}

Keywords: Road safety training program, fatigue, professional drivers, before-after analysis, impact assessment

\section{Introduction}

Worldwide, there is growing evidence that driving fatigue is a major road safety problem, since research surveys reveal that over half of all drivers of private cars drive while being fatigued or drowsy at least once a year [1]. The European Road Safety Observatory points out that fatigue is a contributing factor to a high proportion of road crashes, ranging from $10 \%$ to $20 \%$ [1], while a number of individual studies indicate that fatigue is related to increased crash risk. For example, a study by the Sleep Research Center indicates that driver fatigue causes up to $20 \%$ of accidents on motorways in United Kingdom [2]. In Germany, a study of motorway accidents in Bavaria estimated that 35\% of fatal motorway crashes were due to reduced vigilance, i.e., driver inattention and fatigue [3]. In Australia, VicRoads estimates that 25\%-35\% of road crashes are sleep related (www.vicroads.vic.gov.au./road_safe/index.htm), while in China the Traffic Administration Bureau of Chinese Ministry of Public Security in 2001 reported that the $57 \%$ of 1755 recorded fatigue driving accidents were fatal [4].

Even if drivers are able to recognize when they feel sleepy or tired [5,6], and they also have the knowledge about the effects that cause fatigue [7], it seems that many of them choose to keep driving neglecting the serious consequences in their driving performance and consequently their safety. Potential reasons for driving when sleepy are the poor understanding of fatigue-related crash risk, the underestimating of the speed of transition between sleepiness and sleep, the pressure of reaching destination and the absence of perceived threat of penalty [8,9]. In addition, not only drivers keep driving even if they feel tired or sleepy, but they also adopt strategies to encounter fatigue, such as drink a coffee, open the window, listen to music, talk with passengers, which are only partially effective in coping with fatigue [10,11]. 
There are many studies, which focus on specific high risk groups to be involved in a fatigue-related accident, including young drivers [12], shift workers [13], drivers with sleep disorders [14], and professional drivers [15]. However, no matter the type of user, fatigue burdens drivers' ability to control their vehicles resulting to slower reaction times, poor speed control, reduced vigilance, etc. [16].

Focusing on professional drivers, economic rewards [17] or pressure to reach their destination [18], are considered, along with long hours of driving, sleep deprivation and work schedule, as factors that affect their driving performance and increase significantly risk taking. Statistics prove that professional drivers are at a high risk of road accidents. For example, based on CARE database, tiredness is the main factor for $20 \%$ of crashes involving commercial vehicles, one fourteenth of fatalities involved heavy goods vehicles, and more than $10 \%$ of total fatalities involved professional vehicles [19]. A European crash investigation study revealed that $18.6 \%$ of single truck accidents involved overfatigue/falling asleep conditions [20], while in USA, almost the $25 \%$ of fatal workrelated accidents are road traffic incidents [21].

In literature, three basic categories of driving fatigue countermeasures are recognized. The first one refers to in-car technologies, including for example systems that can detect driver sleepiness through monitoring drivers' eye and head movements. Still, such systems have a significant limitation, which is the weakness to account for individual driver characteristics [22]. The second category regards infrastructure equipment, with the most widely used being the edge or centerline rumble devices [23], and surfacing of the road shoulders with different colored asphalt [24].

Driver related countermeasures, which are the third category of interventions to encounter fatigue, seem to be the most logical and efficient methods to reduce fatigue related accidents [25], since these methods focus on driver behavioral change towards the safe direction through education, training, awareness-raising strategies and mechanisms, and fatigue (risk) management programs. The latter, include both strategies aiming at the reduction of the likelihood that people get fatigued at work, and, also, strategies to minimize any risk addressed by a fatigue-impaired individual in the workplace [26]. Such strategies are usually documented in a "Driver Fatigue Management Plan", which defines the requirements and processes that a company should follow, including, for example trip scheduling, incident management on commercial vehicles, education of drivers in fatigue management, and establishment of appropriate conditions in the workplace [27]. A conceptual framework on how to develop a "Fatigue Risk Management System" was proposed by Dawson and McCulloch (2005), structured under five levels of recognizable hazards, where the levels are related to drivers: sleep opportunity, actual sleep, behavioral symptoms, fatigue-related errors and fatigue-related accidents [28].

Nevertheless, even though the concept of fatigue management programs may be encouraging, there are two basic barriers: the first one refers to the low proportion of implementing such programs, mainly due to economic restrictions, and the second is that these programs are rarely evaluated. However, in a study of Arnold and Hartley (2001), 84 managers of transport companies in Western Australia were interviewed, and findings showed that few companies had an official fatigue management plan, many of the companies that had limits for work hours did not inform drivers about these limits, and a lot of companies were based on drivers' self-regulation for the management of fatigue [29].

Acknowledging the findings of the above literature review, in which fatigue was indicated as a major contributing factor to road accidents, in conjunction with the worldwide statistics' evidence that professional drivers are at a high risk of fatigue-related accidents, this paper aims at investigating the effectiveness of a training program on driving fatigue and assessing the impact of this program on driving behavior, by targeting 162 professional drivers of a leading company in building materials in Greece. 


\section{Methodological Approach}

\subsection{Setting up and Implementing the Training Program}

The Traffic, Transportation and Logistics Laboratory of the University of Thessaly, organized and implemented training program on driving fatigue, aiming at raising awareness of professional drivers on a leading company in building materials in Greece. The program took place in eight cities, hereinafter sites (Kavala, Thessaloniki, Igoumenitsa, Volos, Milaki, Rio, Drapetsona and Heraklion), where the company is established, ensuring national geographical coverage, ran from June 7 to June 28, 2013 and trained 162 employees in total.

Considering the findings of the state-of-the-art review which revealed that even though drivers may have the ability to recognize when they feel tired or sleepy, however there is a high proportion of them who keep driving under fatigue [6], the objectives of the program were specified as the following:

- Raising knowledge of the effective countermeasures for fatigue (i.e. to stop and rest);

- Raising persuasion for avoiding ineffective solutions;

- Increasing risk perception when driving tired;

- Increasing intention for taking a short break when feeling tired;

- Increasing the number of drivers who take a short break when they feel tired, and

- Decreasing the proportion of those drivers who use other solutions to fatigue.

The training program included a 2-hour lecture by the trainer, covering the following topics: the physiological basis of fatigue (e.g., sleep loss and recovery, influence of the circadian biological clock, the effects of shift work, etc.), the institutional and regulatory framework governing professional driving (duration of continuous driving, expected breaks, etc.), the effects of fatigue on driving performance, guidance for personal countermeasure strategies and company policies, and introduction to suspected sleep disorders and referral to specialist treatment.

Right after the lecture, an open discussion session followed, aiming at encouraging drivers to express their personal experiences about driving fatigue and discuss with the trainer the solutions they choose to encounter sleepiness or tiredness, possible mistakes they make, etc. In addition, since one of the basic topics of discussion was the impact of sleep disorders to driving performance, the trainer informed the trainees about this disease and especially the sleep apnoea syndrome and urged them to visit a sleep clinic or laboratory for a check up.

\subsection{Designing the Evaluation}

The Theory of Planned Behavior (TPB) [30], which associates human behavior with attitude and intention taking into account the effect of social norms in the prediction of behavior, was the theoretical model used for the evaluation design of the training program. In fact, based on findings suggesting that TPB can benefit by inserting additional factors [31], an extended version of TPB was applied in this study, with the addition of two variables: past behavior and descriptive norm. Based on the parameters that explain TPB, the measurement variables were constructed and the questionnaire was developed in order to collect the appropriate for the evaluation data. In addition, two periods of measurements were implemented, one before and one after the program realization, so as to enable the indication of any changes in driving behavior attributed to the impact of the training program. 
A face-to-face questionnaire survey was conducted to the trainees right before the beginning of the lecture in each of the eight sites of the company. The total sample that participated in the training program and, consequently to the survey consisted of 162 male drivers with an age of $44.08 \pm 10.5$ years (mean \pm standard deviation). The majority of participants $(74.4 \%)$ drives every day, $17.5 \%$ of them $3-5$ times a week, $6.9 \% 2-5$ times a week, and the rest of them less frequently thus $0.55 \%$ once a week and $0.55 \%$ less often.

Achieving a response rate of $87.7 \%, 142$ out of the 162 above drivers replied and mailed back to the Laboratory a second questionnaire, which had been distributed to them two months after the program. Although the questionnaires were anonymous, the use of a coding system ensured the pairwise data collection before and after the program implementation.

The questionnaire was structured in such a format that allowed information gathering about demographics and measurement of specific variables explaining behavior, i.e., knowledge, behavioral and control beliefs, behavioral intentions, descriptive norms, risk comprehension, past behavior and self-reported behavior. The core part of the questionnaire was responded using a 7-point scale [32], ranging from 1 (Strongly disagree/very unlikely/not at all/never) to 7 (Strongly agree/very likely/a lot/always), depending on the topic addressed. Analytically, the variables tested, the statements or questions expressing them and their coding is presented in Table 1:

Table 1. Variable Classification

\begin{tabular}{|c|c|c|c|}
\hline Statements or questions expressing: & Code & Statements or questions expressing: & Code \\
\hline Knowledge about: & $K N$ & Control beliefs & $C$ \\
\hline Main factors causing driving fatigue & KN1 & $\begin{array}{l}\text { I would stop and rest or plan my trip, if } \\
\text { there were more police controls }\end{array}$ & $\mathrm{C} 1$ \\
\hline Main signs of fatigue & KN2 & $\begin{array}{l}\text { I would stop and rest or plan my trip, if I } \\
\text { had faced a bad experience in my family } \\
\text { or work environment }\end{array}$ & $\mathrm{C} 2$ \\
\hline The most effective solution to fatigue & $\mathrm{KN} 3$ & $\begin{array}{l}\text { I would stop and rest or plan my trip, if } \\
\text { there were more information / raising } \\
\text { awareness campaigns or training } \\
\text { programs }\end{array}$ & $\mathrm{C} 3$ \\
\hline $\begin{array}{l}\text { The high likelihood of get involved in a crash } \\
\text { when driving tired }\end{array}$ & KN4 & Descriptive norms & $D N$ \\
\hline Behavioural beliefs & $B B$ & $\begin{array}{l}\text { My colleagues stop and rest during their } \\
\text { trip }\end{array}$ & DN \\
\hline A good solution to fatigue is to drink a coffee & BB1 & Past behavior & $P B$ \\
\hline $\begin{array}{l}\text { A good solution to fatigue is to open the } \\
\text { window for fresh air }\end{array}$ & BB2 & $\begin{array}{l}\text { Frequency of driving tried in the last } \\
\text { month }\end{array}$ & PB1 \\
\hline A good solution to fatigue is to listen to music & BB3 & $\begin{array}{l}\text { Frequency of falling asleep or almost } \\
\text { falling asleep at the wheel in the last } \\
\text { month }\end{array}$ & PB2 \\
\hline A good solution to fatigue is to stop and rest & BB4 & $\begin{array}{l}\text { Frequency of falling asleep at the wheel } \\
\text { and got involved in a crash }\end{array}$ & PB3 \\
\hline A good solution to fatigue is to plan your trip & BB5 & $\begin{array}{l}\text { Frequency of sleeping less than six hours } \\
\text { the night before your trip }\end{array}$ & PB4 \\
\hline Risk comprehension about: & $R S$ & Self-reported behavior & $\bar{B}$ \\
\hline $\begin{array}{l}\text { Getting involved in an accident or causing an } \\
\text { accident }\end{array}$ & $\mathrm{RS}$ & When I get tired, I stop and rest & B1 \\
\hline Behavioural intentions & INT & When I get tired, I drink a coffee & $\mathrm{B} 2$ \\
\hline $\begin{array}{l}\text { When tired in the next month, I intend to stop } \\
\text { and rest }\end{array}$ & INT1 & When I get tired, I listen to music & B3 \\
\hline I intend to plan my next trips & INT2 & When I get tired, I open the window & B4 \\
\hline $\begin{array}{l}\text { When tired in the next month, I intend to } \\
\text { follow other countermeasures }\end{array}$ & INT3 & & \\
\hline $\begin{array}{l}\text { When tired in the next month, I intend to drive } \\
\text { anyway }\end{array}$ & INT4 & & \\
\hline $\begin{array}{l}\text { When tired in the next month, I intend to quit } \\
\text { my trip }\end{array}$ & INT5 & & \\
\hline
\end{tabular}




\subsection{Analyzing the Data}

The data were analyzed through descriptive and inferential statistics. A number of the drivers' characteristics, including age, years owning a professional driving license and frequency of driving, were analyzed by estimating mean values and standard deviations. In addition, using non-parametric tests, the inferential statistical analysis of the responses was performed.

In order to estimate whether there were any differences in driving behavior before and after the implementation of the training program, hypothesis testing was used: the null hypothesis $\mathrm{H}_{0}$ was that the median difference between the pairs is zero, and the alternative hypothesis $\mathrm{H}_{1}$ was that the median difference is not zero. Chi-square $\left(\mathrm{X}^{2}\right)$ test for homogeneity was used to test differences in characteristics measured by categorical variables (i.e., "yes", "no"), while Wilcoxon Signed-Rank Test and Mann-Whitney $U$ test were performed to assess differences between the samples in characteristics measured on the 7-point scale. A confidence level of 95\% and confidence interval of 5\% were assumed. In addition, in order to investigate the inter-relationships between the individual measurement variables and their relationship with the self-reported variables, bivariate correlations were conducted. Also, for the development of prediction models, linear regression analyses were performed.

\section{Results}

\subsection{Evaluation of the Training Program}

For the evaluation of the training program, trainees were asked to rate ten variables, five of which regarded the concept of the program, i.e. the topic, the content, the duration, the structure and the training material, while four variables concerned the plenitude of the information provided in terms of the factors causing fatigue, the effects on driving skills, prevention countermeasures and effective solutions to reduce fatigue while driving. The last variable was used for the measurement of the degree of convincing drivers to plan their trip and not to drive under fatigue. A 7-point scale was used for the measurement of the above variables, and trainees expressed their opinion grading each question/statement from -1- when they did not agree at all or they were not satisfied at all to -7- when they agreed a lot or they were very satisfied.

The variables used for the evaluation of the concept of the training program were highly rated. Results showed that trainees were very satisfied with the program, and they found the topic of driving fatigue as of high importance and interest (average rating 6.6). Trainees were also very satisfied with the level of information they received during the program about the effective solutions to prevent or encounter fatigue, as well as about the causes and effects of fatigue. The average rating of the relevant variables was 6.7. Lastly, when trainees were asked whether the training program convinced them to plan their trips and not to drive under fatigue, they responded very positively (average rating 6.5).

\subsection{Impact of the Training Program on Driving Behavior}

The results of the impact of the training program on driving behavior are presented in the following paragraphs, in relation with the relevant measurement variables that were tested. Four categorical variables, each of which had two mutually exclusive alternatives "Yes" or "No", were used to describe knowledge. On the other hand, 23 ordinal variables were tested in order to indicate drivers' perceptions on a 7-point scale: 5 addressing behavioral beliefs, 1 risk comprehension, 5 behavioral intentions, 3 control beliefs, 1 descriptive norms, 4 past behavior and 4 self-reported behavior. 
The proportion of the positive responses for the categorical variables and the rating median for the ordinal variables are presented in Table 1, as well as the test results for the comparison between the two phases of the training program which are described through the $\mathrm{z}$-statistic, the calculated effect size $(\mathrm{r}=\mathrm{z} / \sqrt{\mathrm{N}}$, where $\mathrm{N}$ is the total number of observations) and p-value, indicating the strength of the respective evidence.

In the case of knowledge, results showed a significant increase $(p$-value $=0)$ of the proportion of drivers who were aware of the effects of fatigue on driving after the training program (99.3\%), compared to the proportion before the program implementation (98.6\%). Similarly, when testing the percentage of drivers who were aware about the most effective fatigue countermeasure, to stop and rest, it was observed that there was a significant increase between the phases before $(92.3 \%)$ and after $(99.3 \%)$ the training program ( $\mathrm{p}$-value $=0.001$ ). On the other hand, when examining the knowledge in relation to the factors that cause fatigue and that driving tired could involve them to a crash, results showed that all drivers had already this knowledge before the realization of the training program.

When testing the ordinal variables, the positive impact of the training program was also indicated. Specifically, results showed that the average ratings of behavioral beliefs, risk comprehension and behavioral intentions, follow the "positive" direction of change which is addressed by the adoption of effective countermeasures for fatigue, such as trip planning and powernap [33], while, other countermeasures that are falsely used, such as coffee drinking, listening to music, etc., [34] seem to be preferred less by drivers, after the training program.

An increase was also observed in the values of variables related to control beliefs after the implementation of the training program, revealing that if enforcement was stricter $(\mathrm{r}=-$ $0.1, \mathrm{p}$-value $=0.077$ ) or if someone of the family or work environment of the trainees had a bad experience on the roads due to fatigue $(\mathrm{r}=-0.03$, $\mathrm{p}$-value $=0.614)$, that would raise their awareness and urge them to safer driving. Similarly, results showed an increase after the program implementation in trainees' responses referring to their colleagues who stop and rest when tired $(\mathrm{r}=-0.04, \mathrm{p}$-value $=0.523)$.

On the contrary, a decrease was indicated in the frequency of those trainees that drive under fatigue $(\mathrm{r}=-0.05, \mathrm{p}$-value $=0.381)$, the frequency of falling or almost falling asleep at the wheel $(\mathrm{r}=-0.04, \mathrm{p}$-value $=0.515)$ and the frequency of falling asleep and getting involved in a crash $(\mathrm{r}=-0.05, \mathrm{p}$-value $=0.441)$. Even if these differences before and after the program implementation were not statistically significant, still the average ratings reveal that the frequency of risky behavior was already low before the program.

The last category of measurement variables was self-reported behavior, and in this case, it was observed that the realization of the training program had a positive impact on the direction of change in the behavior of the trainees. Specifically, a significant increase was recorded in the adoption of the proposed by the program effective solution to fatigue, to stop and rest when tired $(\mathrm{r}=-0.17, \mathrm{p}$-value $=0.004)$, while a relevant significant reduction was observed in other countermeasures that are falsely used, i.e., coffee drinking $(r=-0.24$, $\mathrm{p}$-value $=0)$, listening to music $(\mathrm{r}=-0.22, \mathrm{p}$-value $=0)$ and opening the window $(\mathrm{r}=-0.26, \mathrm{p}$ value $=0$ ). 


\section{Table 2. Proportion of Positive Responses, Rating Median and Summary Test Results for Comparison between the Phases of the Training Program - Before vs. after the Training}

\begin{tabular}{|c|c|c|c|c|c|}
\hline \multirow[t]{2}{*}{ Categorical variables } & \multicolumn{2}{|c|}{$\begin{array}{c}\text { Proportion of positive } \\
\text { responses }\end{array}$} & \multirow{2}{*}{\multicolumn{2}{|c|}{ Test parameters relation }} & \multirow{2}{*}{$\begin{array}{l}\text { p-value } \\
\text { B vs. A }\end{array}$} \\
\hline & B & $\mathbf{A}$ & & & \\
\hline Knowledge for fatigue effects & $98.6 \%$ & $99.3 \%$ & \multicolumn{2}{|c|}{$\mathrm{p}_{\mathrm{A}}>\mathrm{p}_{\mathrm{B}}$} & $0 *$ \\
\hline $\begin{array}{l}\text { Knowledge for most effective } \\
\text { countermeasure }\end{array}$ & $92.3 \%$ & $99.3 \%$ & \multicolumn{2}{|c|}{$\mathrm{p}_{\mathrm{A}}>\mathrm{p}_{\mathrm{B}}$} & $0.001 *$ \\
\hline \multirow{2}{*}{ Ordinal variables } & \multicolumn{2}{|c|}{ Average rating } & \multirow{2}{*}{ z-statistic } & \multirow{2}{*}{ Effect size (r) } & p-value \\
\hline & $\mathbf{B}$ & $\mathbf{A}$ & & & B vs. A \\
\hline \multicolumn{6}{|c|}{ Behavioral beliefs: “A good solution to fatigue is to..." } \\
\hline Drink a coffee & 3.57 & 2.94 & -3.338 & -0.2 & $0.001 *$ \\
\hline Open the window for fresh air & 4.14 & 3.40 & -3.763 & -0.22 & $0^{*}$ \\
\hline Listen to music & 3.26 & 2.48 & -4.344 & -0.26 & $0 *$ \\
\hline Stop and rest for $15-20$ minutes & 5.92 & 6.13 & -1.033 & -0.06 & 0.301 \\
\hline Plan my trip & 6.15 & 6.53 & -2.476 & -0.15 & $0.013^{*}$ \\
\hline \multicolumn{6}{|l|}{ Risk comprehension about: } \\
\hline $\begin{array}{l}\text { Getting involved or causing an } \\
\text { accident }\end{array}$ & 6.15 & 6.51 & -1.893 & -0.11 & 0.058 \\
\hline \multicolumn{6}{|c|}{ Behavioral intentions: "When tired in the next month, I intend to..." } \\
\hline Stop and rest for $15-20$ minutes & 5.15 & 6.44 & -6.054 & -0.4 & $0 *$ \\
\hline Plan my trip & 5.98 & 6.51 & -3.016 & -0.18 & $0.003 *$ \\
\hline Follow other solutions & 4.25 & 3.61 & -2.643 & -0.16 & $0.008^{*}$ \\
\hline Drive anyway & 3.85 & 2.86 & -4.070 & -0.24 & $0^{*}$ \\
\hline Interrupt my trip & 4.55 & 6.09 & -6.135 & -0.36 & $0^{*}$ \\
\hline \multicolumn{6}{|c|}{ Control beliefs: "I would stop and rest or I would plan my trip, if..." } \\
\hline Enforcement was more strict & 4.33 & 4.75 & -1.766 & -0.1 & 0.077 \\
\hline $\begin{array}{l}\text { Someone of my family or } \\
\text { colleagues had a bad experience }\end{array}$ & 4.83 & 4.91 & -0.504 & -0.03 & 0.614 \\
\hline $\begin{array}{l}\text { Campaigns or training programs } \\
\text { were implemented more often }\end{array}$ & 5.39 & 5.36 & -0.221 & -0.01 & 0.825 \\
\hline \multicolumn{6}{|l|}{ Descriptive norms: } \\
\hline $\begin{array}{l}\text { My colleagues stop and rest during } \\
\text { their trip }\end{array}$ & 5.05 & 5.13 & -0.639 & -0.04 & 0.523 \\
\hline \multicolumn{6}{|l|}{ Past behavior: } \\
\hline Frequency of driving under fatigue & 2.20 & 2.09 & -0.876 & -0.05 & 0.381 \\
\hline $\begin{array}{l}\text { Frequency of falling asleep or } \\
\text { almost falling asleep at the wheel }\end{array}$ & 1.29 & 1.23 & -0.652 & -0.04 & 0.515 \\
\hline $\begin{array}{l}\text { Frequency of falling asleep and } \\
\text { getting involved in a crash }\end{array}$ & 1.11 & 1.06 & -0.770 & -0.05 & 0.441 \\
\hline $\begin{array}{l}\text { Frequency of sleeping less than } 6 \\
\text { hours before a planned trip }\end{array}$ & 2.94 & 2.77 & -0.768 & -0.05 & 0.443 \\
\hline \multicolumn{6}{|c|}{ Self-reported behavior: “When I get tired...” } \\
\hline I stop and rest for $15-20$ minutes & 6.15 & 6.50 & -2.880 & -0.17 & $0.004^{*}$ \\
\hline I drink a coffee & 4.28 & 3.44 & -4.052 & -0.24 & $0 *$ \\
\hline I listen to music & 3.73 & 2.99 & -3.725 & -0.22 & $0 *$ \\
\hline I open the window & 5.01 & 4.08 & -4.452 & -0.26 & $0^{*}$ \\
\hline
\end{tabular}

Additionally, in order to further assess the impact of the training program on driving behavior, two more tests were conducted, and the sample was formulated and distinguished into clusters, based on:

- Age: A1 cluster: drivers aged 18-45 years old and A2 cluster: drivers older than 45 years. Approximately, the $56 \%$ of the drivers belong to A1 cluster, and the rest $44 \%$ to the $\mathrm{A} 2$ cluster.

- Size of trucks fleet of the site: FI cluster: sites with fleet more than 15 trucks, and F2 cluster: sites with less or equal to 15 trucks. Volos and Drapetsona sites 
belong to F1 cluster and the rest sites thus Kavala, Thessaloniki, Rio, Igoumenitsa, Milaki and Heraklion belong to F2 cluster.

For the needs of this paper, the results of the comparison between the above clusters regard the period after the implementation of the training program, in order to investigate its actual impact on the behavior of professional drivers.

In Table 3, the rating median for the ordinal variables and the test results of the comparison between cluster A1 and A2 are presented. It was observed, that although there were indicated differences in the average rating of the responses between the two clusters in all tested measurement variables, however these differences were not statistically significant. Focusing on behavioral beliefs, it was observed that, after the training program, the average rating of younger drivers follow more the "positive' direction of change, which is addressed by the main message of the program thus to stop and rest when getting tired while driving ( $\mathrm{p}$-value=0.486). On the other hand, the variables addressing older drivers' behavioral beliefs to other countermeasures that are falsely used, such as coffee drinking, listening to music, opening the window were lower rated.

Examining drivers' intentions, results showed that the average rating of older drivers follow more the "positive" direction of change, meaning that older drivers intend more to stop and rest when they get tired and less to adopt other countermeasures ( $p$-value $=0.278$ ). Similarly, it seems that situations such as more strict enforcement, bad experiences, etc. would affect more the older drivers than the younger ones, something that was addressed by the ratings of the variables related to control beliefs.

Focusing on the results of the comparison between the two clusters regarding past behavior, it was indicated that older drivers were more conscious after the training program realization, since they were driving under fatigue ( $\mathrm{p}$-value $=0.233$ ) or they had fallen asleep at the wheel ( $\mathrm{p}$-value $=0.136)$, less frequently than the younger drivers.

Lastly, when reporting self-behavior, older drivers stated that they stopped and rested when they were tired more often than younger drivers ( $p$-value $=0.474)$, while they followed other countermeasures to deal with fatigue less often than their younger colleagues.

\section{Table 3. Average Rating and Summary Test Results for Comparison between the Phases of the Training Program - Age Clustering}

\begin{tabular}{|c|c|c|c|c|}
\hline \multirow{2}{*}{ Ordinal variables } & \multicolumn{2}{|c|}{ Average rating } & \multirow{2}{*}{$\begin{array}{l}\text { Test parameters } \\
\text { relation }\end{array}$} & \multirow{2}{*}{$\begin{array}{l}\text { p-value } \\
\text { A1 vs. A2 }\end{array}$} \\
\hline & $\mathbf{A 1}$ & A2 & & \\
\hline \multicolumn{5}{|c|}{ Behavioral beliefs: "A good solution to fatigue is to..." } \\
\hline Drink a coffee & 3.11 & 2.67 & $r_{1}>r_{2}$ & 0.187 \\
\hline Open the window for fresh air & 3.52 & 3.03 & $r_{1}>r_{2}$ & 0.131 \\
\hline Listen to music & 2.44 & 2.45 & $r_{1}>r_{2}$ & 0.844 \\
\hline Stop and rest for $15-20$ minutes & 6.11 & 6.07 & $r_{1}>r_{2}$ & 0.486 \\
\hline Plan my trip & 6.47 & 6.57 & $r_{1}<r_{2}$ & 0.338 \\
\hline \multicolumn{5}{|l|}{ Risk comprehension about: } \\
\hline Getting involved or causing an accident & 6.51 & 6.52 & $r_{1}<r_{2}$ & 0.899 \\
\hline \multicolumn{5}{|c|}{ Behavioral intentions: "When tired in the next month, I intend to..." } \\
\hline Stop and rest for $15-20$ minutes & 6.40 & 6.48 & $r_{1}<r_{2}$ & 0.278 \\
\hline
\end{tabular}




\begin{tabular}{|c|c|c|c|c|}
\hline Plan my trip & 6.55 & 6.42 & $r_{1}>r_{2}$ & 0.55 \\
\hline Follow other solutions & 3.80 & 3.27 & $r_{1}>r_{2}$ & 0.139 \\
\hline Drive anyway & 2.93 & 2.78 & $r_{1}>r_{2}$ & 0.758 \\
\hline Interrupt my trip & 6.04 & 6.27 & $r_{1}<r_{2}$ & 0.176 \\
\hline \multicolumn{5}{|c|}{ Control beliefs: "I would stop and rest or I would plan my trip, if..." } \\
\hline Enforcement was more strict & 4.43 & 4.95 & $r_{1}<r_{2}$ & 0.092 \\
\hline $\begin{array}{l}\text { Someone of my family or colleagues had a } \\
\text { bad experience }\end{array}$ & 4.76 & 4.95 & $r_{1}<r_{2}$ & 0.626 \\
\hline $\begin{array}{l}\text { Campaigns or training programs were } \\
\text { implemented more often }\end{array}$ & 5.27 & 5.37 & $r_{1}<r_{2}$ & 0.483 \\
\hline \multicolumn{5}{|l|}{ Descriptive norms: } \\
\hline My colleagues stop and rest during their trip & 4.96 & 5.37 & $r_{1}<r_{2}$ & 0.136 \\
\hline \multicolumn{5}{|l|}{ Past behavior: } \\
\hline Frequency of driving under fatigue & 2.27 & 1.97 & $r_{1}>r_{2}$ & 0.233 \\
\hline $\begin{array}{l}\text { Frequency of falling asleep or almost falling } \\
\text { asleep at the wheel }\end{array}$ & 1.33 & 1.12 & $r_{1}>r_{2}$ & 0.136 \\
\hline $\begin{array}{l}\text { Frequency of falling asleep and getting } \\
\text { involved in a crash }\end{array}$ & 1.11 & 1.0 & $r_{1}>r_{2}$ & 0.070 \\
\hline $\begin{array}{l}\text { Frequency of sleeping less than } 6 \text { hours } \\
\text { before a planned trip }\end{array}$ & 2.93 & 2.62 & $r_{1}>r_{2}$ & 0.202 \\
\hline \multicolumn{5}{|l|}{ Self-reported behavior: “When I get tired...” } \\
\hline I stop and rest for 15-20 minutes & 6.44 & 6.62 & $r_{1}<r_{2}$ & 0.474 \\
\hline I drink a coffee & 3.45 & 3.35 & $r_{1}>r_{2}$ & 0.79 \\
\hline I listen to music & 3.04 & 2.83 & $r_{1}>r_{2}$ & 0.459 \\
\hline I open the window & 4.12 & 3.83 & $r_{1}>r_{2}$ & 0.509 \\
\hline
\end{tabular}

In Table 4, the rating median for the ordinal variables and the test results of the comparison between cluster F1 and F2 are presented.

\section{Table 4. Average Rating and Summary Test Results for Comparison between the Phases of the Training Program - Fleet Clustering}

\begin{tabular}{|c|c|c|c|c|}
\hline \multirow{2}{*}{ Ordinal variables } & \multicolumn{2}{|c|}{ Average rating } & \multirow{2}{*}{$\begin{array}{c}\text { Test parameters } \\
\text { relation }\end{array}$} & \multirow{2}{*}{$\begin{array}{c}\text { p-value } \\
\text { F1 vs. F2 }\end{array}$} \\
\hline & F1 & F2 & & \\
\hline \multicolumn{5}{|c|}{ Behavioral beliefs: “A good solution to fatigue is to..." } \\
\hline Drink a coffee & 2.93 & 2.95 & $r_{1}<r_{2}$ & 0.938 \\
\hline Open the window for fresh air & 3.10 & 3.79 & $r_{1}<r_{2}$ & 0.056 \\
\hline Listen to music & 2.21 & 2.82 & $r_{1}<r_{2}$ & 0.056 \\
\hline Stop and rest for 15-20 minutes & 6.16 & 6.08 & $r_{1}>r_{2}$ & 0.691 \\
\hline Plan my trip & 6.65 & 6.37 & $r_{1}>r_{2}$ & 0.188 \\
\hline
\end{tabular}




\begin{tabular}{|c|c|c|c|c|}
\hline \multicolumn{5}{|l|}{ Risk comprehension about: } \\
\hline Getting involved or causing an accident & 6.60 & 6.39 & $r_{1}>r_{2}$ & 0.078 \\
\hline \multicolumn{5}{|l|}{ Behavioral intentions: "When tired in the next month, I intend to..." } \\
\hline Stop and rest for $15-20$ minutes & 6.46 & 6.39 & $r_{1}>r_{2}$ & 0.097 \\
\hline Plan my trip & 6.46 & 6.42 & $r_{1}>r_{2}$ & 0.065 \\
\hline Follow other solutions & 6.55 & 6.45 & $r_{1}<r_{2}$ & $0.002 *$ \\
\hline Drive anyway & 2.25 & 3.65 & $r_{1}<r_{2}$ & $0 *$ \\
\hline Interrupt my trip & 6.30 & 5.82 & $r_{1}>r_{2}$ & $0.001^{*}$ \\
\hline \multicolumn{5}{|l|}{ Control beliefs: "I would stop and rest or I would plan my trip, if..." } \\
\hline Enforcement was more strict & 4.64 & 4.90 & $r_{1}<r_{2}$ & 0.456 \\
\hline Someone of my family or colleagues had a bad experience & 5.32 & 4.37 & $r_{1}>r_{2}$ & $0.006^{*}$ \\
\hline Campaigns or training programs were implemented more often & 5.36 & 5.35 & $r_{1}>r_{2}$ & 0.794 \\
\hline \multicolumn{5}{|l|}{ Descriptive norms: } \\
\hline My colleagues stop and rest during their trip & 5.16 & 5.10 & $r_{1}>r_{2}$ & 0.478 \\
\hline \multicolumn{5}{|l|}{ Past behavior: } \\
\hline Frequency of driving under fatigue & 1.85 & 2.40 & $r_{1}<r_{2}$ & $0.019 *$ \\
\hline Frequency of falling asleep or almost falling asleep at the wheel & 1.15 & 1.34 & $r_{1}<r_{2}$ & 0.156 \\
\hline Frequency of falling asleep and getting involved in a crash & 1.04 & 1.08 & $r_{1}<r_{2}$ & 0.207 \\
\hline Frequency of sleeping less than 6 hours before a planned trip & 2.63 & 2.95 & $r_{1}<r_{2}$ & 0.436 \\
\hline \multicolumn{5}{|l|}{ Self-reported behavior: "When I get tired...” } \\
\hline I stop and rest for $15-20$ minutes & 6.70 & 6.24 & $r_{1}>r_{2}$ & $0^{*}$ \\
\hline I drink a coffee & 3.24 & 3.71 & $r_{1}<r_{2}$ & 0.168 \\
\hline I listen to music & 2.70 & 3.35 & $r_{1}<r_{2}$ & 0.05 \\
\hline I open the window & 3.79 & 4.45 & $r_{1}<r_{2}$ & 0.072 \\
\hline
\end{tabular}

In this case, results showed that drivers who are occupied in sites with large fleets intend more to stop and rest whey they get tired or interrupt their trip compared to drivers of smaller fleet sites ( $\mathrm{p}$-value $=0.097$ ). In addition, it was observed that a bad experience in the family or the work environment would affect more the drivers of large fleets who stated that they would stop and rest more often that their colleagues of smaller fleets (pvalue $=0.006$ ). Lastly, the drivers of larger fleets self-reported that when they get tired they stop and rest more frequently than the drivers of smaller fleets ( $p$-value $=0)$. The above differences between the two clusters were statistically significant.

\subsection{Inter-relationships between Measurement Variables}

Based on the main objectives of the training program thus to increase the awareness of the professional drivers that the most effective solution to encounter fatigue is to stop and 
rest when feeling tired, and, on the other hand, to decrease the number of drivers who follow other ineffective countermeasures when tired, i.e., to drink a coffee, listen to music or open the window for fresh air, two alternative tests were run, respectively. For the needs of the present paper, these tests were based on the responses of the drivers after the implementation of the training program. Also, based on the results of the previous section, this analysis regards the fleet clusters F1 and F2, where statistically significant differences were observed in the responses of the two groups.

Applying the first test, an effort was made to investigate the inter-relationships between a number of measurement variables and their relationship with the variable addressing self-reported behavior towards stopping and resting when tired. In addition, the first test included the development of a model predicting the impact of the training program in terms of affecting drivers to stop and rest whey they get tired. On the other hand, the aim of the second test was to investigate the inter-relationships between a number of measurement variables and their relationship with the variable addressing self-reported behavior towards following other solutions to fatigue than stopping and resting. Once again, a prediction model was developed associated with the effectiveness of the program to convince drivers not to use ineffective solutions when they have to deal with fatigue.

Table 5 presents the bivariate correlations of the individual variables and their relationship with the variable addressing self-reported behavior towards stopping and resting for those drivers belonging to $\mathrm{F} 1$ cluster. In this case, the dependent variable thus self-reported behavior towards stopping and resting (variable B1 of Table 1) was correlated with behavioral belief that a good solution to fatigue is to stop and rest (variable BB4 of Table 1), risk comprehension about getting involved in an accident or causing an accident (variable RS of Table 1), the four variables addressing past behavior (PB1, PB2, PB3 and PB4 of Table 1) and descriptive norm addressing drivers' perception on actual situations, such as "My colleagues stop and rest during their trip" (variable DN of Table 1). Also, B1 was correlated with variables regarding control beliefs (C1, C2 and $\mathrm{C} 3$ of Table 1), and in this case, using alpha test [35] the responses of drivers were combined into one variable, hereinafter $\mathrm{C} 123$, with a value of Cronbach alpha higher than 0.6 .

Results showed that there is a significant neutral positive relationship between descriptive norm and the variable addressing self-reporting behavior towards stopping and resting when tired $(\beta=0.239, \mathrm{p}$-value $<0.05)$ (Table 5). Positive relationships were also observed between behavior and behavioral belief, risk comprehension, behavioral intention, control beliefs and past behavior 3, however these correlations were not significant. On the other hand, a negative relationship was indicated between behavior and the variables referring to past behavior 1,2 and 4, showing that when the values of behavior increase, the values of past behavior decrease. Specifically, a significant neutral negative relationship was observed between behavior and past behavior PB1 ( $\beta=-0.36$, pvalue $<0.01)$.

Table 5. Bivariate Correlations of the Individual Variables and their Relationship with the Variable Addressing Self-Reported Behavior Towards Stopping and Resting when Tired - Cluster F1

\begin{tabular}{|c|c|c|c|c|c|c|c|c|c|c|c|}
\hline Variables & Code & 1. & 2. & 3. & 4. & 5. & 6. & 7. & 8. & 9. & 10. \\
\hline $\begin{array}{l}\text { 1. Self-reported } \\
\text { behavior_1 }\end{array}$ & B1 & - & & & & & & & & & \\
\hline $\begin{array}{l}\text { 2. Behavioral } \\
\text { belief_4 }\end{array}$ & BB4 & .052 & - & & & & & & & & \\
\hline $\begin{array}{l}\text { 3. Risk } \\
\text { comprehension }\end{array}$ & $\mathrm{RS}$ & .022 & -.155 & - & & & & & & & \\
\hline $\begin{array}{l}\text { 4. Behavioral } \\
\text { intention_1 }\end{array}$ & INT1 & .101 & .046 & $.361 \%$ & - & & & & & & \\
\hline
\end{tabular}




\begin{tabular}{|c|c|c|c|c|c|c|c|c|c|c|c|}
\hline $\begin{array}{l}\text { 5. Descriptive } \\
\text { norm }\end{array}$ & DN & $.239 *$ & -.010 & .135 & .061 & - & & & & & \\
\hline $\begin{array}{l}\text { 6. Control } \\
\text { belief_123 }\end{array}$ & $\mathrm{C} 123$ & .013 & .213 & .019 & .117 & .126 & - & & & & \\
\hline $\begin{array}{l}\text { 7. Past } \\
\text { behavior_1 }\end{array}$ & PB1 & $-.36^{* * *}$ & .184 & $-.302 * *$ & $-.278^{*}$ & $-.269 *$ & $-.323 * *$ & - & & & \\
\hline $\begin{array}{l}\text { 8. Past } \\
\text { behavior_2 }\end{array}$ & PB2 & -.048 & .088 & -.182 & -.169 & -.196 & -.109 & $.468 * *$ & - & & \\
\hline $\begin{array}{l}\text { 9. Past } \\
\text { behavior_3 }\end{array}$ & PB3 & .052 & .070 & .062 & .068 & -.100 & -.094 & .173 & $.351 * *$ & - & \\
\hline $\begin{array}{l}\text { 10. Past } \\
\text { behavior_4 }\end{array}$ & PB3 & -.114 & -.063 & -.131 & -.198 & -.090 & -.193 & $.421 * *$ & .138 & .112 & - \\
\hline \multicolumn{12}{|l|}{$*_{p \text {-value }<.05}$} \\
\hline$* * p$-value $<.01$ & & & & & & & & & & & \\
\hline
\end{tabular}

Focusing on the second test that was conducted, the dependent variable was selfreported behavior towards following other solutions to fatigue than stopping and resting, and was constructed by the combination of the variables B2, B3 and B4 of Table 1 (hereinafter B234), which record self-reported behavior of the drivers who choose to drink a coffee, listen to music and open the window for fresh air, when they get tired while driving. For the combination of B2, B3 and B4, alpha test was used again. Similarly, control beliefs in this case was constructed by the combination of variables $\mathrm{C} 1$, $\mathrm{C} 2$ and $\mathrm{C} 3$ of Table 1 (hereinafter $\mathrm{C} 123$ ) and behavioral beliefs by the combination of variables BB1, BB2 and BB3 of Table 1 (hereinafter BB123). The dependent variable was also correlated with the variable expressing drivers' intention to follow other countermeasures to deal with fatigue (variable INT3 of Table 1), while risk comprehension (RS), descriptive norm (DN), past behavior PB1, PB2, PB3 and PB4 were the same variables as those used in the first test. The results of the bivariate correlations of the above measurement variables and their relationship with the dependent variable addressing self-reported behavior towards following other solutions to fatigue, i.e. drinking a coffee, listening to music and opening the window for fresh air, are presented in Table 6.

Table 6. Bivariate Correlations of the Individual Variables and their Relationship with the Variable Addressing Self-Reported Behavior Towards following other Solutions to Fatigue than Stopping and Resting When Tired - Cluster F1

\begin{tabular}{|c|c|c|c|c|c|c|c|c|c|c|c|}
\hline Variables & Code & 1. & 2. & 3. & 4. & 5. & 6. & 7. & 8. & 9. & 10. \\
\hline $\begin{array}{l}\text { 1. Self-reported } \\
\text { behavior_234 }\end{array}$ & B234 & - & & & & & & & & & \\
\hline $\begin{array}{l}\text { 2. Behavioral } \\
\text { belief_123 }\end{array}$ & BB123 & $.689 * *$ & - & & & & & & & & \\
\hline $\begin{array}{l}\text { 3. Risk } \\
\text { comprehension }\end{array}$ & $\mathrm{RS}$ & $-.249 *$ & -.045 & - & & & & & & & \\
\hline $\begin{array}{l}\text { 4. Behavioral } \\
\text { intention_3 }\end{array}$ & INT3 & $.752 * *$ & $.689 * *$ & $-.307 * *$ & - & & & & & & \\
\hline $\begin{array}{l}\text { 5. Descriptive } \\
\text { norm }\end{array}$ & DN & $-.361 * *$ & -.144 & .135 & -.098 & - & & & & & \\
\hline $\begin{array}{l}\text { 6. Past } \\
\text { behavior_1 }\end{array}$ & PB1 & $.354^{* *}$ & .085 & $-.302 * *$ & .164 & $-.269 *$ & - & & & & \\
\hline $\begin{array}{l}\text { 7. Past } \\
\text { behavior_2 }\end{array}$ & $\mathrm{PB} 2$ & .231 & .083 & -.182 & .077 & -.196 & $.468 * *$ & - & & & \\
\hline $\begin{array}{l}\text { 8. Past } \\
\text { behavior_3 }\end{array}$ & PB3 & -.020 & -.137 & .062 & -.117 & -.100 & .173 & $.351 * *$ & - & & \\
\hline
\end{tabular}




\begin{tabular}{|l|l|l|l|l|l|l|l|l|l|l|l|}
\hline $\begin{array}{l}\text { 9. Past } \\
\text { behavior_4 }\end{array}$ & PB4 & .179 & .047 & -.131 & $\mathbf{. 2 5 2 *}$ & -.090 & $\mathbf{. 4 2 1} * *$ & .138 & .112 & - & \\
\hline $\begin{array}{l}\text { 10. Control } \\
\text { belief_123 }\end{array}$ & $\mathrm{C} 123$ & -.118 & -.032 & .019 & -.034 & .126 & $\mathbf{- . 3 2 3 * *}$ & -.109 & -.094 & -.193 & - \\
\hline$* p$-value .05 & \\
\hline$* * p$-value $<.01$
\end{tabular}

In this case, results showed that behavioral beliefs B123, behavioral intention INT3 and past behavior PB1 are significantly correlated with the variable addressing selfreporting behavior B234. More specifically, there is a strong positive relationship between behavioral beliefs B123 and behavior B234 $(\beta=0.689$, p-value $<0.01)$, a strong positive relationship between behavioral intention INT3 and behavior B234 $(\beta=0.752$, pvalue $<0.01$ ), and a neutral positive relationship between past behaviour PB1 and behaviour B234 $(\beta=0.231$, $\mathrm{p}$-value $<0.01)$. Positive relationships were also observed between behavior and past behavior PB2 and past behavior PB4, however these correlations were not significant. On the other hand, a negative relationship was indicated between behavior and the variables referring to risk comprehension, descriptive norm, past behavior PB3 and control beliefs C123.

Similarly, in Tables 7 and 8, the results of the bivariate correlations for the second cluster F2 are presented. It was observed that behavioral intention and descriptive norm are significantly correlated with the variable addressing self-reporting behavior towards stopping and resting when tired. A neutral positive relationship was observed between behavior and behavioral intention $(\beta=0.364$, $\mathrm{p}$-value $<0.01)$, and also a neutral positive relationship between behavior and descriptive norm $(\beta=0.381$, $\mathrm{p}$-value $<0.01)$. Positive relationships were also observed between behavior and behavioral beliefs B123 and risk comprehension. On the other hand, a negative relationship was observed between behavior and the variables referring control beliefs $\mathrm{C} 123$ and the four variables addressing past behavior PB1, PB2, PB3 and PB4. Specifically, results showed a neutral negative relationship between behavior and control beliefs $(\beta=-0.275$, $\mathrm{p}$-value $<0.05)$, a neutral negative relationship between behavior and PB1 $(\beta=-0.378, \mathrm{p}$-value $<0.01)$, a neutral negative relationship between behavior and PB2 $(\beta=-0.316$, $\mathrm{p}$-value $<0.05)$, a negligible negative relationship between behavior and PB3 $(\beta=-0.105$, p-value $>0.05)$, and a neutral negative relationship between behavior and PB4 $(\beta=-0.294$, $\mathrm{p}$-value $<0.05)$.

In the second case, results showed that behavioral beliefs BB123, behavioral intention INT3 and past behavior PB1 are significantly correlated with the variable addressing selfreporting behavior towards following other solutions to fatigue than stopping and resting when tired (B234). To this end, a strong positive relationship was indicated between behavior and behavioral beliefs $(\beta=0.822$, $\mathrm{p}$-value $<0.01)$, a strong positive relationship between behavior and behavioral intention $(\beta=0.686$, $\mathrm{p}$-value $<0.01)$, and a neutral positive relationship between behavior and past behavior PB1 $(\beta=0.282$, p-value $<0.05)$. Positive relationships were also observed between behavior and risk comprehension, past behavior PB2, PB3, PB4 and control beliefs C123. On the other hand, a negligible negative relationship was observed between behavior and descriptive norm DN $(\beta=-0.118$, pvalue $>0.05)$.

Table 7. Bivariate Correlations of the Individual Variables and their Relationship with the Variable Addressing Self-Reported Behavior Towards Stopping and Resting when Tired - Cluster F2

\begin{tabular}{|c|c|c|c|c|c|c|c|c|c|c|c|}
\hline Variables & Code & 1. & 2. & 3. & 4. & 5. & 6. & 7. & 8. & 9. & 10. \\
\hline $\begin{array}{l}\text { 1. Self-reported } \\
\text { behavior_1 }\end{array}$ & B1 & - & & & & & & & & & \\
\hline 2. Behavioral & BB4 & .019 & - & & & & & & & & \\
\hline
\end{tabular}




\begin{tabular}{|c|c|c|c|c|c|c|c|c|c|c|c|}
\hline \multicolumn{12}{|l|}{ belief_4 } \\
\hline $\begin{array}{l}\text { 3. Risk } \\
\text { comprehension }\end{array}$ & RS & .133 & $.251 *$ & - & & & & & & & \\
\hline $\begin{array}{l}\text { 4. Behavioral } \\
\text { intention_1 }\end{array}$ & INT1 & $.364 * *$ & $.310^{*}$ & $.305^{*}$ & - & & & & & & \\
\hline $\begin{array}{l}\text { 5. Control } \\
\text { belief_123 }\end{array}$ & $\mathrm{C} 123$ & $-.275^{*}$ & .173 & .118 & .054 & - & & & & & \\
\hline $\begin{array}{l}\text { 6. Descriptive } \\
\text { norm }\end{array}$ & $\mathrm{DN}$ & $.381 * *$ & .109 & .088 & $.298 *$ & .010 & - & & & & \\
\hline $\begin{array}{l}\text { 7. Past } \\
\text { behavior_1 }\end{array}$ & PB1 & $-.378 * *$ & -.107 & -.156 & $-.277 *$ & .139 & -.178 & - & & & \\
\hline $\begin{array}{l}\text { 8. Past } \\
\text { behavior_2 }\end{array}$ & PB2 & $-.316^{*}$ & -.145 & -.050 & -.162 & .062 & $-.250 *$ & $.521 * *$ & - & & \\
\hline $\begin{array}{l}\text { 9. Past } \\
\text { behavior_3 }\end{array}$ & PB3 & -.105 & -.190 & -.154 & -.149 & -.074 & -.089 & $.266^{*}$ & $.501 * *$ & - & \\
\hline $\begin{array}{l}\text { 10. Past } \\
\text { behavior_4 }\end{array}$ & PB3 & $-.294 *$ & $-.291 *$ & $-.265^{*}$ & -.238 & -.049 & -.036 & $.456 * *$ & .218 & .238 & \\
\hline \multicolumn{12}{|l|}{${ }^{*} p$-value $<.05$} \\
\hline$* * p$-value $<.01$ & & & & & & & & & & & \\
\hline
\end{tabular}

Table 8. Bivariate Correlations of the Individual Variables and their Relationship with the Variable Addressing Self-Reported Behavior Towards following other Solutions to Fatigue than Stopping and Resting when Tired - Cluster F2

\begin{tabular}{|c|c|c|c|c|c|c|c|c|c|c|c|}
\hline Variables & Code & 1. & 2. & 3. & 4. & 5. & 6. & 7. & 8. & 9. & 10. \\
\hline $\begin{array}{l}\text { 1. Self-reported } \\
\text { behavior_234 }\end{array}$ & B234 & - & & & & & & & & & \\
\hline $\begin{array}{l}\text { 2. Behavioral } \\
\text { belief_123 }\end{array}$ & BB123 & $.822 * *$ & - & & & & & & & & \\
\hline $\begin{array}{l}\text { 3. Risk } \\
\text { comprehension }\end{array}$ & RS & .001 & -.128 & - & & & & & & & \\
\hline $\begin{array}{l}\text { 4. Behavioral } \\
\text { intention_3 }\end{array}$ & INT3 & $.686 * *$ & $.714 * *$ & -.085 & - & & & & & & \\
\hline $\begin{array}{l}\text { 5. Descriptive } \\
\text { norm }\end{array}$ & $\mathrm{DN}$ & -.118 &.-170 & .088 & -.211 & - & & & & & \\
\hline $\begin{array}{l}\text { 6. Past } \\
\text { behavior_1 }\end{array}$ & PB1 & $.282 *$ & .131 & -.156 & .080 & -.178 & - & & & & \\
\hline $\begin{array}{l}\text { 7. Past } \\
\text { behavior_2 }\end{array}$ & PB2 & .206 & .014 & -.050 & -.090 & $-.25^{*}$ & $.521 * *$ & - & & & \\
\hline $\begin{array}{l}\text { 8. Past } \\
\text { behavior_3 }\end{array}$ & PB3 & .093 & .053 & -.154 & .050 & -.089 & $.266^{*}$ & $.501 * *$ & - & & \\
\hline $\begin{array}{l}\text { 9. Past } \\
\text { behavior_4 }\end{array}$ & PB4 & .226 & $.253 *$ & $-.265^{*}$ & .144 & -.036 & $.456 * *$ & .218 & .238 & - & \\
\hline $\begin{array}{l}\text { 10. Control } \\
\text { belief_123 }\end{array}$ & C123 & .144 & .067 & .118 & .026 & .010 & .139 & .062 & -0.74 & -0.49 & - \\
\hline \multicolumn{12}{|l|}{$* p$-value $<.05$} \\
\hline$* * p$-value $<.01$ & & & & & & & & & & & \\
\hline
\end{tabular}

\subsection{Prediction Model Development and Testing}

The last objective of this study was to develop prediction models in order to investigate which factors are associated with the likelihood of drivers to stop and rest when they get 
tired while driving, as well as the respective likelihood of drivers to follow other solutions to deal with fatigue, such as to drink a coffee, listen to music or open the window for fresh air. The results of the four prediction models, two for each cluster FI and F2 are presented in Tables 9-12.

In the first case and for cluster F1, behavioral belief_4 (BB4), risk comprehension (RS), past behavior PB1 and descriptive norm (DN) were used as predictors of the dependent variable thus self-reported behavior towards stopping and resting when tired. Results showed that the strongest predictor was risk comprehension. The overall model was a significant predictor of behavior $(F(4,79)=1.606)$ and accounted for $10 \%$ of the variance. Analytically, the relationship of each predictor with behavior is presented in Table 9.

\section{Table 9. Linear Regression of the Individual Variables and their Relationship with the Variable Recording Self-Reported Behavior Towards stopping and Resting when Tired - Cluster F1}

\begin{tabular}{|c|c|c|c|c|c|c|}
\hline Variable & Code & B & Std. Error & Beta & $\mathbf{t}$ & Sig. \\
\hline Behavioral belief_4 & BB4 & .003 & .058 & .005 & .045 & .964 \\
\hline Risk comprehension & RS & .050 & .122 & .049 & .410 & .683 \\
\hline Descriptive norm & DN & .042 & .054 & .088 & .775 & .441 \\
\hline Past behavior_1 & PB1 & -.160 & .085 & -.231 & -1.896 & .062 \\
\hline Constant & & 6.434 & 1.00 & & 6.435 & 0 \\
\hline \multicolumn{7}{|c|}{ Adjusted $R^{2}=.1 ; F(4,75)=1.606$} \\
\hline
\end{tabular}

In the second model and for cluster F1, descriptive norm DN, past behavior PB1, past behavior PB2, past behavior PB4, behavioral belief BB123 and behavioral intention INT3 were used as predictors of the dependent. Results showed that the strongest predictor was behavioral belief BB123 (p-value-0). The overall model was a significant predictor of behavior $(\mathrm{F}(6,73)=35.9$, p-value- 0$)$ and accounted for $73 \%$ of the variance. Analytically, the relationship of each predictor with behavior is presented in Table 10.

Table 10. Linear Regression of the Individual Variables and their Relationship with the Variable Recording Self-Reported Behavior Towards following other Solutions to Fatigue than Stopping and Resting when Tired - Cluster F1

\begin{tabular}{|l|l|l|l|l|l|l|}
\hline Variable & Code & B & Std. Error & Beta & t & Sig. \\
\hline Descriptive norm & DN & -.226 & .062 & -.221 & -3.659 & $0 *$ \\
\hline Past behavior_1 & PB1 & .338 & .103 & .227 & 3.299 & $.002 *$ \\
\hline Past behavior_2 & PB2 & .199 & .248 & .052 & .801 & .426 \\
\hline Past behavior_4 & PB4 & -.012 & .059 & -0.12 & -.199 & .843 \\
\hline Behavioral belief_123 & BB123 & .428 & .095 & .359 & 4.510 & $0 *$ \\
\hline Behavioral intention_3 & INT3 & .361 & .068 & .440 & 5.350 & $0 *$ \\
\hline Constant & 1.272 & .519 & & 2.449 & .017 \\
\hline Adjusted $\boldsymbol{R}^{2}=\mathbf{7 3 ;} \mathbf{F ( 6 , 7 3 ) = 3 5 . 9 7 *}$ & & & & & \\
\hline *p-value $<.05$ &
\end{tabular}

Similarly, two more models were developed addressed to cluster F2, and the results are presented in the following tables. When the dependent variable was behavior towards stopping and resting when tired, it was observed that the strongest predictor was 
behavioral intention INT1 (p-value<0.05). The overall model was a significant predictor of behavior $(\mathrm{F}(9,52)=3.47$, p-value-0) and accounted for $27 \%$ of the variance. Analytically, the relationship of each predictor with behavior is presented in Table 11.

Table 11. Linear Regression of the Individual Variables and their Relationship with the Variable Recording Self-Reported Behavior Towards Stopping and Resting when Tired - Cluster F2

\begin{tabular}{|c|c|c|c|c|c|c|}
\hline Variable & Code & B & Std. Error & Beta & $\mathrm{t}$ & Sig. \\
\hline Behavioral belief_4 & BB4 & -.030 & .061 & -.059 & -.482 & .632 \\
\hline Risk comprehension & RS & -.006 & .107 & -.007 & -.059 & .953 \\
\hline Behavioral intention_1 & INT1 & .317 & .140 & .287 & 2.267 & $.028 *$ \\
\hline Descriptive norm & DN & .207 & .075 & .327 & 2.765 & $.008 *$ \\
\hline Past behavior_1 & PB1 & -.056 & .090 & -.099 & -.619 & .538 \\
\hline Past behavior_2 & PB2 & .175 & .190 & .168 & .924 & .360 \\
\hline Past behavior_3 & PB3 & -.494 & .314 & -.239 & -1.571 & .122 \\
\hline Past behavior_4 & PB4 & -.043 & .050 & -.106 & -.854 & .397 \\
\hline Control belief_123 & $\mathrm{C} 123$ & -.162 & .072 & -.267 & -.854 & .397 \\
\hline Constant & & 4.716 & 1.227 & & 3.843 & 0 \\
\hline \multicolumn{7}{|c|}{ Adjusted $R^{2}=.27 ; F(9,52)=3.47 *$} \\
\hline${ }^{*} p$-value $<.05$ & & & & & & \\
\hline
\end{tabular}

Lastly, when the dependent variable was behavior towards following other solutions to fatigue such as opening the window for fresh air, listening to music, etc., it was observed that the strongest predictor was behavioral belief B123 ( $\mathrm{p}$-value $=0)$. The overall model was a significant predictor of behavior $(\mathrm{F}(9,52)=22.39$, p-value- 0$)$ and accounted for $76 \%$ of the variance. Analytically, the relationship of each predictor with behavior is presented in Table 12.

Table 12. Linear Regression of the Individual Variables and their Relationship with the Variable Recording Self-Reported Behavior Towards Following other

Solutions to Fatigue than Stopping and Resting when tired - Cluster F2

\begin{tabular}{|c|c|c|c|c|c|c|}
\hline Variable & Code & B & Std. Error & Beta & $\mathbf{t}$ & Sig. \\
\hline Behavioral belief_123 & BB123 & .699 & .099 & .655 & 7.066 & $0^{*}$ \\
\hline Risk comprehension & RS & .231 & .132 & .116 & 1.744 & .087 \\
\hline Behavioral intention_3 & INT3 & .212 & .081 & .249 & 2.613 & $.012 *$ \\
\hline Descriptive norm & DN & .132 & .096 & .096 & 1.385 & .172 \\
\hline Past behavior_1 & PB1 & .159 & .111 & .128 & 1.427 & .159 \\
\hline Past behavior_2 & $\mathrm{PB} 2$ & .468 & .238 & .205 & 1.967 & .055 \\
\hline Past behavior_3 & PB3 & -.424 & .380 & -.094 & -1.115 & .270 \\
\hline Past behavior_4 & PB4 & -.015 & .062 & -.017 & -.240 & .811 \\
\hline Control belief_123 & $\mathrm{C} 123$ & .013 & .088 & .009 & .143 & .887 \\
\hline Constant & & -2.027 & 1.211 & & -1.673 & 0.1 \\
\hline \multicolumn{7}{|c|}{ Adjusted $R^{2}=.76 ; F(9,52)=22.39 *$} \\
\hline${ }^{*} p$-value $<.05$ & & & & & & \\
\hline
\end{tabular}




\section{Conclusions}

This paper aimed at assessing the impact of a training program on driving fatigue, targeting 162 professional drivers of a leading company in building materials in Greece. The main message of the program, which was to raise drivers' awareness about the most effective solution to fatigue, was successfully reached by the trainees. Specifically, results showed a significant increase in average rating of drivers' intention to stop and rest for 15-20 minutes ( $\mathrm{p}$-value $=0$ ) and a significant decrease to follow other less effective solutions ( $\mathrm{p}$-value $=0.008)$. The findings of variables testing the self-reported behavior of trainees, revealed that the training program affected their behavior in the positive direction of change, resulting in a statistically significant increase of the average frequency that they stop and rest when they feel tired (p-value $=0.004)$.

When clustering the sample based on age and the size of trucks fleet of the sites, results showed that there were not any significant differences between the two age clusters regarding their responses in the measurement variables of the evaluation design used for the study. On the other hand, results showed that drivers who are occupied in sites with large fleets intend more to stop and rest when they get tired or interrupt their trip compared to drivers of smaller fleet sites. It is assumed that this is owning to the fact that large fleets operate under a more stringent regulatory scheme, complying with some standards (e.g., ISO) as opposed to small fleets, usually being operated by truck drivers, who are also truck owners, so they do not report to an employer.

Also, it was observed that a bad experience in the family or the work environment would affect more the drivers of large fleets who stated that they would stop and rest more often than their colleagues of smaller fleets.

In addition, based on the main objectives of the training program thus to increase the awareness of the professional drivers that the most effective solution to encounter fatigue is to stop and rest when feeling tired, and, on the other hand, to decrease the number of drivers who follow other ineffective countermeasures, an effort was made to investigate the inter-relationships between a number of measurement variables and their relationship with the variables addressing self-reported behavior, and to develop prediction models. The model with the highest prediction power was indicated in the case of cluster F2 when the dependent variable was the self-reported behavior towards following other solutions to fatigue than stopping and resting when tired (Adjusted $\mathrm{R}^{2}=.76 ; \mathrm{F}(9,52)=22.39^{*}$ ).

\section{Acknowledgments}

This paper is a revised and expanded version of a paper entitled "Assessing the impact of a fatigue training program on driving behavior" presented at the $6^{\text {th }}$ Pan-Hellenic Conference on Road Safety, Athens, Greece, March 12-13, 2015.

\section{References}

[1] ERSO (2008). Fatigue. Retrieved January 20, 2015 from www.erso.eu.

[2] J. Horne and L. Reyner, "Sleep Related Vehicle Accidents", Sleep Research Laboratory, Loughborough University, (2000).

[3] W. Hell, "Road Inattention and Other Causative Factors in Fatal Highway Crashes", Proceedings of the 41th Annual Conference of the Association for the Advancement of Automotive Medicine, Orlando, USA, (1997), November 10-11.

[4] Traffic Administration Bureau of Chinese Public Security Ministry. Statistics Annals of Road Traffic Accident of People's Republic of China (2010). Traffic Administration Bureau of Chinese Public Security Ministry, (2011).

[5] G. Keeklund and T. Akerstedt, "Sleepiness in long distance truck driving: an ambulatory EEG study of night driving”, Ergonomics, vol. 36, (1993), pp. 1007-17.

[6] J. A. Horne and S. D. Baulk, "Awareness of sleepiness when driving", Psychophysiology, vol. 41, pp. 161-165.

[7] S. Nordbakke and F. Sageberg, "Sleepy at the wheel: knowledge, symptoms and behaviour among car drivers", Transportation Research Part F, vol. 10, (2007), pp. 1-10. 
[8] J. V. Baranski, R. A. Pigeau and R. G. Angus, "On the ability to Self-monitor Cognitive Performance During Sleep Deprivation: A calibration Study”, Journal of Sleep Res., (1993).

[9] New South Waless Roads and Traffic Authority. Road Traffic Accidents in New South Wales. 1994 Statistical Statement Year ending 31 December 1994, Sydney (AUST):RTA, (1995).

[10] J. Horne and L. Reyner, "Evaluation of "in-car" Countermeasures to Sleepiness", Cold Air and Radio, Sleep, vol. 21, no. 1, (1988).

[11] L. Reyner and J. Horne, "Suppression of Sleepiness in Drivers: Combination of Caffeine with a Short Nap", Psychophysiology, vol. 34, (1997).

[12] J. A. Horne and L. A. Reyner, "Sleep related vehicle accidents", British Medical Journal, vol. 310, (1995), pp. 565-567.

[13] M. Gkrizioti, A. Mastrokostas, A. B. Haiditch, E. Panagopoulou and A. Benos, "Shift Work and Traffic Accidents among Nursing Personnel", Nosileftiki, vol. 49, no. 3, (2010), pp. 305-314.

[14] B. Yee, A. Campbell, R. Beasley and A. Neill, "Sleep disorders: a potential role in New Zealand motor vehicle accidents", Intern Med Journal, vol. 32, pp. 297-304.

[15] S. McKernon, "A literature review on driver fatigue among drivers in the general public", NZ Transport Agency research report, vol. 342, (2008), pp. 62.

[16] S. D. Baulk, S. N. Biggs, K. J. Reid, C. J. van den Heuvel and D. Dawson, "Chasing the silver bullet: measuring driver fatigue using simple and complex tasks", Accident Analysis and Prevention, vol. 40, no. 1 , (2008), pp. 396-402.

[17] P. K. Arnold, L. R. Hartley, A. Corry, D. Hochstadt, F. Penna and A. M. Feyer, "Hours of work, and perceptions of fatigue among truck drivers", Accident Analysis and Prevention, vol. 29, no, 4, (1997), pp. 471-477.

[18] I. D. Brown, "Prospects for technological countermeasures against driver fatigue", Accident Analysis and Prevention, vol. 29, no. 4, (1997), pp. 525-531.

[19] CARE, 2014. http://ec.europa.eu/transport/road_safety/specialist/statistics/index_en.htm, retrieved April, 2014.

[20] J. R. Dalziel and R. F. S. Job, "Motor vehicle accidents, fatigue and optimism bias in taxi drivers", Accident Analysis and Prevention, vol. 29, no. 4, (1997), pp. 489-494.

[21] G. Toscano and J. Windau, "The changing character of fatal work injuries", Monthly Labour Rev., (1994), pp. 17-28.

[22] C. C. Liu, S. G. Hosking and M. G. Lennı, "Predicting driver drowsiness using vehicle measures: recent insights and future challenges", Journal of Safety Research, vol. 40, (2009), pp. 239-245.

[23] A. Anund, G. Kecklund, A. Vadeby, M. Hjälmdahl and T. Ekerstedt, "The alerting effect of hitting a rumble strip - a simulator study with sleepy drivers", Accident Analysis and Prevention, vol. 40, (2008), pp. 1970-1976.

[24] F. Rosey, J.-M. Auberlet, J. Bertrand and P. Plainchault, "Impact of perceptual treatments on lateral control during driving on crest vertical curves: a driving simulator study", Accident Analysis and Prevention, vol. 40, (2008), pp. 1513-1523.

[25] N. Merat and H. Jamson, "The effect of three low-cost engineering treatments on driver fatigue: A driving simulator study", Accident Analysis and Prevention, vol. 50, (2013), pp. 8-15.

[26] P. Gander, L. Hartley, D. Powell, P. Cabon, E. Hitchcock, A. Mills and S. Popkin, "Fatigue risk management: Organizational factors at the regulatory and industry/company level", Accident Analysis and Prevention, no. 43, (2011), pp. 573-590.

[27] SafetyNet (2009). Fatigue, retrieved March, 7, 2016.

[28] D. Dawson and K. McCulloch, "Managing Fatigue: It's about sleep", Sleep Medicine Reviews, vol. 9, (2005), pp. 365-380.

[29] P. K. Arnold and L. R. Hartley, "Policies and practices of transport companies that promote or hinder the management of driver fatigue", Transportation Research Part F, vol. 4, pp. 1-17.

[30] I. Ajzen, "The theory of planned behavior", Organizational Behavior and Human Decision Processes, vol. 50, (1991), pp. 179-211.

[31] S. Forward and A. Kazemi, (Editors), G. Adamos, K. Ausserer, K. Brijs, T. Brijs, S. Daniels, M. Divjak, J. Haupt, B. Krol, J. Malasek, T. Nathanail, R. O. Phillips, R. Risser, K. Tamis, P. Ullberg, T. Vaa and V. Zabukovec, "A theoretical approach to assess road safety campaigns: Evidence from seven European countries", CAST project. Belgian Road Safety Institute (IBSR-BIVV), Brussels, Belgium, (2009).

[32] I. Ajzen, "Constructing a TPB questionnaire: conceptual and methodological considerations", Retrieved July, 27, 2012 from http://www.people.umass.edu/aizen/pdf/tpb.measurement.pdf, (2002).

[33] H. P. Van Dongen, G. Maislin, J. M. Mullington and D. F. Dinges, "The cumulative cost of additional wakefulness: dose-response effects on neurobehavioral functions and sleep physiology from chronic sleep restriction and total sleep deprivation", Sleep, vol. 26, no. 2, (2003), pp. 117-126.

[34] S. Heatherley, "Caffeine withdrawal, sleepiness, and driving performance: What does the research really tell us?", Nutritional Neuroscience, vol. 12, no. 3, (2011).

[35] L. J. Cronbach, "Coefficient alpha and the internal structure of tests", Psychometrical, vol. 16, no. 3, pp. 297-334 


\section{Authors}

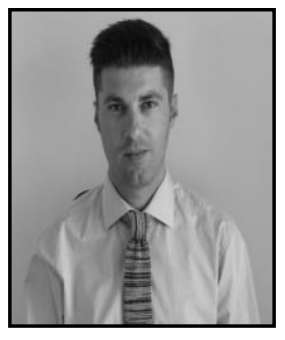

Giannis Adamos (Born in Volos, Greece, May 14, 1978)

- Research Associate, Traffic, Transportation and Logistics Laboratory, University of Thessaly, Volos, Greece

- Education: 5-year Diploma in Civil Engineering (1998-2004), MSc in Applied Engineering \& Systems' Simulation (2004-2006), PhD Candidate (2008-today)

- Publications: More than 50 scientific papers published in journals and conference proceedings and book chapters in 5 books.

- Fields of research: Road safety, driving behavior simulation, public transport, logistics.

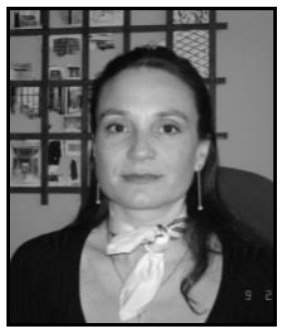

Eftihia Nathanail, $\mathrm{PhD}$, MSc (born in Thessaloniki Greece)

- Position: Head of the Traffic, Transportation and Logistics Laboratory, Ass. Professor in Transportation Systems Design and Evaluation, Department of Civil Engineering, University of Thessaly

- Education: Diploma in Surveying Engineering, Aristotle University of Thessaloniki (1988), M.Sc. in Civil Engineering (Transportation), University of Miami, USA (1991), PhD in Civil Engineering Aristotle University of Thessaloniki (1996).

- Scientific activities: Committee Member of RESTRAIL, EU, ECOMOBILITY, ECOCITY, EU, Hazardous Material Transportation (AT040), TRB, national representative of COST-TU1004, Support Framework Business program 2000-2006 and Foresight Technology, Greece, European Thematic Network ROSEBUD.

- Publications: more than 80 scientific papers published in journals and conference proceedings and book chapters in 7 books.

- Fields of research: transportation planning and design, intelligent transportation systems, multicriteria evaluation and optimization. 
International Journal of Transportation

Vol.5, No.1 (2017) 